\title{
A Neurobiological Model for Near-Death Experiences
}

\author{
Juan C. Saavedra-Aguilar, M.D. \\ Juan S. Gómez-Jeria, Lic.Q. \\ University of Chile
}

\begin{abstract}
The authors present a neurobiological model for near-death experiences (NDEs) in an attempt to correlate the biological and psychological domains. This model is based on temporal lobe dysfunction, hypoxia/ischemia, stress, and neuropeptide/neurotransmitter imbalance. They describe and discuss the fundamental contribution of the language system in the construction of verbal reports of NDEs. This model could be seen as a complement to other explanatory domains.
\end{abstract}

The phenomenology of near-death experiences (NDEs) has been described by several authors (Greyson, 1981, 1983a, 1983b, 1985; Greyson and Stevenson, 1980; Grosso, 1981, Pasricha and Stevenson, 1980; Sabom, 1982; Sabom and Kreutziger, 1977a). Attempts to explain the NDE range from metaphysical explanations (Sabom and Kreutziger, 1977a) to psychodynamic ones (Greyson, 1983). These correspond to different levels of explanation, each one valid only in its own domain. In this paper, we restrict ourselves to the neurobiological level of explanation.

The authors acknowledge financial support for this work from the University of Chile (DTI Project Q-2442) and FONDECYT (Project 1111-1988).

Dr. Saavedra-Aguilar is Assistant Professor in the Department of Neurological Sciences in the Faculty of Medicine, University of Chile. Lic. Gómez-Jeria is Assistant Professor in the Faculty of Sciences at the University of Chile. Requests for reprints should be addressed to Dr. Saavedra-Aguilar at the Universidad de Chile, Facultad de Medicina, Departamento de Ciencias Neurologicas, Av. Jose Miguel Infante 555, Santiago, Chile; or to Lic. Gómez-Jeria at the Universidad de Chile, Facultad de Ciencias, Departamento de Quimica, Casilla 653, Santiago, Chile. 
Temporal lobe dysfunction and endorphins have been proposed to play a role in NDEs (Carr, 1981, 1982). Since that hypothesis was developed a decade ago, the neurosciences have undergone an impressive development. Thus, it would be interesting to integrate recent relevant data into a coherent and up-to-date NDE model. The object of this paper is to provide a neurophysiological NDE model, based mainly on temporal lobe dysfunction, but also including some recent developments, such as stress-induced release of neuropeptides and other neurotransmitters. A more general objective will be to use this model as an example of how neurosciences and psychology can be correlated.

\section{The Phenomenology of Near-Death Experiences}

NDEs are defined as the mental experiences "reported by people who have been seriously injured or ill but unexpectedly recovered and by people who had anticipated imminent death in potentially fatal situations but escaped uninjured" (Greyson and Stevenson, 1980, p. 1193). Some of the main experiential components of NDEs are (Gabbard, Twemlow, and Jones, 1981; Greyson, 1983; Greyson and Stevenson, 1980; Sabom and Kreutziger, 1977a).

(1) hearing noises during the early stages of the experience;

(2) a strong emotional feeling, in about half the cases, the reported feeling being one of positive affect, with euphoria, bliss, peacefulness, with little cognitive content, preceding any life review or other visions;

(3) the out-of-body experience (OBE), in which the subject reports seeing his or her own body, commonly from above, or feels as if he or she is "leaving" the body;

(4) the tunnel experience, in which the subject feels as if he or she is passing through a dark enclosed space, often surrounded by strange sounds, and feels pulled towards a bright light;

(5) encounters with unearthly beings (beings of light, religious figures, deceased and living acquaintances, etc.) and panoramic realms;

(6) the life review, in which there is a more or less complete awareness of past events, the mnesic experience appearing most commonly all at once rather than in a certain sequence;

(7) unusual visual and sensory phenomena such as lights, auras, colors, figures, and unusual somatic, auditory, olfactory, and gustatory phenomena; and 
(8) distortion of the sense of time, in the majority of cases, time seeming to pass more slowly.

A relevant question is whether NDEs occur only to those people who really were near death, or to those in other situations as well. Bruce Greyson and Ian Stevenson (1980) reported that NDEs in their study were precipitated by medical illness $(40 \%)$, traumatic injury $(37 \%)$, surgical operation $(13 \%)$, childbirth $(7 \%)$, and drug ingestion $(4 \%)$. Moreover, $47 \%$ of their subjects reported some kind of drug or alcohol ingestion the day of the experience. Therefore, being really near death does not appear to be a necessary condition to having an NDE. Nevertheless, a common characteristic of those subjects was that they were in a stressful situation. On the other hand, NDEs do not appear to be extremely uncommon; Michael Sabom and Sarah Kreutziger (1977b) found them in $51 \%$ of illness and accident victims.

Kenneth Ring (1980) considered NDEs as unfolding in a five-stage temporal sequence: a feeling of peace and contentment, an OBE, entering a world of darkness, the appearance of a brilliant light, and the experience of "entering the light." The percentage of subjects experiencing these different stages ranged from $60 \%$ for the first stage to $10 \%$ for the last one.

\section{Neuropathophysiological Correlations}

\section{Temporal Lobe Epilepsy and NDEs}

Temporal lobe epilepsy (TLE) is the generic term applied to seizures that begin not only in the temporal lobe, but also in limbic structures like the amygdala, the hippocampus, the insula, the orbitofrontal cortex, and the cingulate gyrus. The mental phenomena manifested during TLE seizures and electrical stimulation of the brain are variable, appearing in different combinations, and can be classified as (Taylor and Lochery, 1987; Hausser-Haw and Bancaud, 1987; Schenk and Bear, 1981; Halgren, Walter, Cherlow, and Crandall, 1978; Gloor, Olivier, Quesney, Andermann, and Horowitz, 1982; Mesulam, 1981, 1986; Penfield, 1955; Frederiks, 1985, Critchley, 1979):

(1) somatosensory phenomena, such as focal pain, tingling, cramps, tickling, and burning;

(2) motor phenomena, such as complex automatisms, localized twitches, tremors, and lipsmacking; 
(3) autonomic phenomena, such as nausea, blurred vision, shortness of breath, rising or sinking feelings, and vertigo;

(4) hallucinations or illusions in virtually all sensory modalities, including visual phenomena such as geometric shapes, distorted color perception, fully formed complex images, mythological presences, metamorphopsia, micropsia, and macropsia;

(5) emotions, such as anxiety, forced negative mental content, sadness, depression, peacefulness, serenity, fear, hunger, panic, and guilt; and

(6) and experiences, such as memory flashbacks, ideas or feelings of a presence, déjà vu, déjà veçu, depersonalization, illusions of possession, multiple personality, mind/body dissociation, autoscopy, out-of-body experiences, jamais $v u$, strange and ineffable mental feelings, faraway and cosmic feelings, fugue episodes, and distortions of time and space.

This impressive variability is due to the complex functional and anatomical structures involved in the origin and propagation of the seizure. Limbic structures have extended connections with sensory association areas. Cortical information from frontal and temporal association areas converges onto the entorhinal and perirhinal cortices. The amygdala also projects to these areas, from which the perforant path into the hippocampus arises. Another important input to the entorhinal area comes from the presubiculum, which, in turn, receives input from the parietal lobe and the cingulate cortex, thus providing another form of extrinsic afferent input to the entorhinal cortex.

The hippocampus projects to the entorhinal cortex, from which the efferents to the neocortex arise. The amygdala receives direct efferents from unimodal and polymodal sensory association cortices, and projects back to sensory association areas, as well as to most other areas of the cortex. The hippocampal formation receives direct neocortical input only from the multimodal posterior parahippocampal gyrus, while input from the sensory association areas, which project directly to the amygdala, reach the hippocampus only after a relay in the entorhinal cortex (Isaacson, 1982; Seifert, 1983; Mesulam, 1986; Saunders, Rosene, and van Hoesen, 1988; Saunders and Rosene, 1988).

This complex network clearly shows that the amygdala, the hippocampal formation, and the entorhinal areas are directly or indirectly connected to association areas, thus providing the anatomical basis for 
the polymodal processing of information coming from sensory, motor, and subcortical areas of the brain. Therefore, these limbic structures seem to play a pivotal role in perception, memory, attention, emotion, motor, and autonomic functions.

Several factors that account for the variability of TLE phenomenology are also relevant for NDEs within our model. First, one of the functions of the limbic system is to encode the subject's personal biography in episodic memory (Gloor, 1982; Gloor, Olivier, Quesney, Andermann, and Horowitz, 1982; Tulving, 1987). Therefore, limbic temporal lobe discharges should reflect individual past experiences. Second, the aura pattern of TLE seizures can be dependent upon the actual mental state (Rayport and Ferguson, 1974).

Third, the origin of the seizure and the spread of the afterdischarge can vary from subject to subject and from time to time (Wieser, 1983). This possibility is supported by experimental studies on gustatory hallucinations during epileptic seizures, showing that these hallucinations appear only when the afterdischarge propagates to the opercular region (Hausser-Hauw and Bancaud, 1987). Fourth, it is difficult to determine "whether the patient's verbal report represents a sufficiently accurate description of what he or she actually experiences, or whether a rather vague sensation is being elaborated on" (Gloor, Olivier, Quesney, Andermann, and Horowitz, 1982, p. 141). We will discuss this important aspect later.

Fifth, it has been shown that amnesia occurring during medial temporal lobe paroxysms can be highly variable, ranging from nearnormal memory to complete amnesia, implying recall of different types of mental phenomena by different individuals (Halgren and Wilson, 1985). Also, it is known that the quantity of firing neurons correlates well with the different clinical manifestations of the seizure (Babb, Wilson, and Isokawa-Akesson, 1987). Furthermore, it has been noted that experiential, autonomic, emotional, and dissociative phenomena are more commonly associated with right hemisphere seizures (Gupta, Jeavons, Hughes, and Covanis, 1983; Mesulam, 1986; Schenk and Bear, 1981).

It bears stressing that the list of the mental phenomena seen in TLE and stereotaxic electrical stimulation of the temporal lobe includes all the NDE phenomenology. Therefore, if NDEs share some characteristics of TLE phenomena, it does not appear too far-reaching that they may also share some common pathophysiological mechanisms. The question that arises is how that abnormal brain functioning comes about in NDEs. 
Neuropeptides, Neurotransmitters, and NDEs

There is extensive evidence that some endogenous opioid peptides play a fundamental role in the regulation of excitability of the hippocampus. Leu-5-enkephalin and met-5-enkephalin have excitatory actions in the hippocampal pyramidal cells, especially in the CA1 field, and $\beta$-endorphin has a naloxone-reversible seizurogenic effect (McGinty, Kanamatsu, Obio, and Hong, 1986), while its intraventricular administration can induce nonconvulsive epileptogenic actions on the spontaneous electroencephalographic pattern of rats, especially from limbic areas. These effects occur at doses with no analgesic effects (Henriksen, Bloom, McCoy, Ling, and Guillemin, 1978). In any case, opioid peptides can alter seizure sensitivity to different stimuli probably through indirect effects on cholinergic, monoaminergic, and aminoacidergic functions of the limbic system (Gellman and McNamara, 1984; Woodbury, 1984). In the rat hippocampus, opioids appear to act via a disinhibitory mechanism in the dentate gyrus and in the CA1 field, probably on inhibitory $\gamma$-aminobutyric acid (GABA) interneurons (Neumaier, Mailheau, and Chavkin, 1988).

These findings support the idea that changes in the normal balance of neuropeptides and neurotransmitters could contribute to abnormal limbic activity. It has also been shown that, during moderate stress and brain trauma, there is a liberation of endogenous peptides (Kelly, 1982; McIntosh, Fernyak, and Faden, 1986; Brooks, Burrin, Cheetaw, Hall, Yeo, and Williams 1988), which could explain the appearance of hallucinations in stressful situations in alert, nonpsychotic patients (Modai and Cygielman, 1986).

Therefore, in the stressful situation that always accompanies the NDE, there is a possibility of endogenous peptide liberation resulting in alterations of limbic activity (Leitner, 1984). This mechanism may contribute by itself to the NDE mechanism; we will discuss below its link to hypoxia/ischemia. If endogenous peptide-induced changes in limbic activity do play a role in NDEs, then we could expect similar phenomena during situations of extreme psychological stress, such as kidnapping, torture, or panic attacks.

Clinical evidence supporting the role of endorphins in NDEs comes from I. R. Judson and E. Wiltshaw's (1983) observations of a man found comatose and requiring intensive treatment that ended with an intravenous dose of naloxone. Within a minute he awoke in an agitated state, and later reported an NDE-like experience that apparently was 
interrupted by the naloxone, suggesting that the experience may have been mediated by opioid peptides.

This limbic epileptogenic mechanism does not exclude the possibility of additional mechanisms, such as serotonin dysfunction, that have been suggested to have a role in the action of some hallucinogenic drugs (Glennon, 1985). In any case, NDE-like phenomena have been reported under the influence of LSD, hashish, and ketamine, supporting the possible involvement of various neurotransmitter systems (Siegel and Hirschman, 1984; Rogo, 1984; Siegel, 1980).

\section{Hypoxia/ischemia and NDEs}

It can be assumed that in NDEs, by definition, individuals are in a sudden and stressful situation with diminished cerebral blood flow and oxygen. This state may produce limbic discharges by at least two mechanisms: hypoxia/ischemia directly inducing limbic neuronal depolarization and discharge, and endogenous discharge of neurotransmitters, including neuropeptides, triggered by stress. In relation to the first possibility, it is known that one of the most sensitive targets of oxygen deprivation is the hippocampus and its related structures (Siesjo and Wieloch, 1986). Among hippocampal pyramidal cells, those in the CA1 field are most vulnerable to hypoxia (Plum and Pulsinelly, 1986). In vitro studies of CA1 cells during hypoxia in rats showed that evoked inhibitory postsynaptic potentials were abolished within 3 minutes of hypoxic exposure, while evoked excitatory postsynaptic potentials were maintained for about 20 minutes, and neural spikes elicited by depolarization were preserved (Fujiwara, Higashi, Shimoji, and Yoshimura, 1987). Thus, the balance between excitatory and inhibitory synapses is altered during hypoxia. Furthermore, it has been proposed that this balance, mediated by GABA and N-methylD-aspartate (NMDA) receptors, modulates the normal excitability of hippocampal cells (Dingledine, Hynes, and King, 1986). Since it is known that during hypoxia/ischemia there is a release of an excitatory aminoacid that activates the NMDA receptor (Fagg, 1985), hypoxia/ ischemia could induce direct abnormal discharges in hippocampal cells during an NDE. Hypoxia also lowers acetylcholine levels in the brain (Gibson and Blaas, 1979), which might also contribute to NDE phenomenology if we accept that such a decrease is associated with hallucinations, delirium, dreams, amnesia, and analgesia (Hong, Woo, Suh, Park, and Lee, 1987). 


\section{A Pathophysiological Model for NDEs}

Considering all the elements presented above, we suggest the following temporal pattern for the mechanism giving rise to NDEs:

(1) a traumatic event, such as cardiac arrest, surgery, trauma, or illness;

(2) appearance of brain stress;

(3) release of neuropeptides and/or neurotransmitters;

(4) decrease in oxygen tension in the brain, affecting mainly limbic structures;

(5) abnormal excitation of target tissues;

(6) epileptiform discharges in the hippocampus and amygdala;

(7) afterdischarges propagating through limbic connections (the fornix, septal areas, hypothalamus, entorhinal areas, and neocortical areas) towards more distant regions; and

(8) a recovery process, involving a rise in the rate of firing of inhibitory neurons, release of GABA, increase in oxygen tension, and energetic recovery.

Of course, this model is a general one, and the actual contribution of each of these factors in a given case could vary and be influenced by the individual's previous biological and psychological structure. For example, in one case hypoxia/ischemia may be the main factor inducing epileptogenic discharges, with minor contribution from neuropeptide release, while in another case there may be a significant contribution from neurotransmitters and neuropeptides. At any rate, this temporal pattern cannot last more than about 7-10 minutes before irreversible brain damage and associated clinical deficits will occur.

Several temporal biological/experiential correlations for NDEs, based on the above model, are presented in Figure 1:

(1) The traumatic event does not appear to be correlated with specific NDE experiential phenomena, and in general induces a variable alteration in consciousness.

(2) In the stage of brain stress and hypoxia/ischemia, there is vasoconstriction and consequent reduction of blood supply to sensory organs, probably mediated by sympathetic adrenergic neurons, although changes in the release of vasopressin by the pituitary cannot be excluded (Clark, Yang, and Janal, 1984). It is highly probable that the decrease in blood flow could induce discharges in the cells of the organ of Corti, 


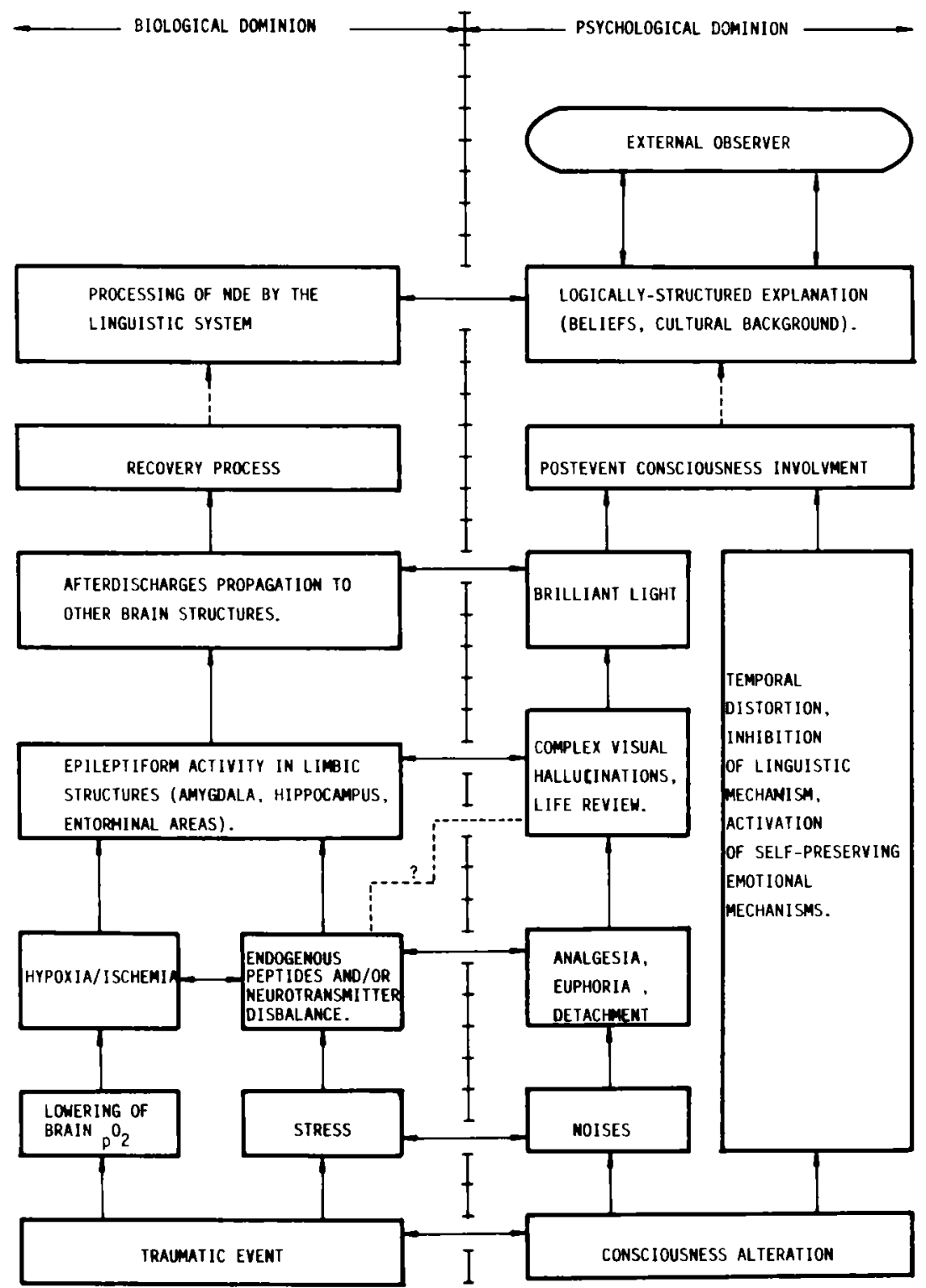

Figure 1

Temporal biological-experiential correlations for Near-Death Experiences. 
producing the noises reported in the early stages of the experience.

(3) Stress-induced release of $\beta$-endorphin and/or other neuropeptides is correlated with euphoria, analgesia, and long-lasting detachment, probably through an action at the $\mu$ and $\delta$ receptors located in limbic structures, such as the nucleus accumbens, amygdala, and hippocampus (Kelly, 1982; Hiller, Itzhak, and Simon, 1986; McLean, Rothman, and Herkenham, 1986).

(4) The common final pathway of both hypoxia/ischemia and endogenous peptide release is epileptiform activity in the hippocampus and other limbic structures, producing a life review and complex visual hallucinations. As is well known, some portions of the limbic system, like the hippocampus and the amygdala (Mishkin and Appenzeller, 1987), play an important role in the normal retrieval of stored information. This episodic memory enables people to remember personal experiences from the past (Tulving, 1987), and is clearly different from the other major types of long-term memory that permit the individual to have a knowledge of the world. The life review in the NDE can be understood as an abnormal retrieval of episodic memory contents by the dysfunctional limbic areas. In contrasting personal episodic memory contents to other memories, William James (1890) wrote that "the former have a warmth and intimacy about them of which the latter are completely devoid" (p. 331), which clearly implies that episodic memory has a high emotional content. Moreover, given that limbic system structures have been associated with only episodic memory, it is not strange that dysfunctions at this level can only produce episodic memory disturbances. Out-of-body experiences (OBEs), which appear frequently in TLE (Frederiks, 1969), can be considered as being complex visual hallucinations, which have been correlated with electrical stimulation of the amygdala and the hippocampal formation (Halgren, Walter, Cherlow, and Crandall, 1978; Gloor, Olivier, Quesney, Andermann, and Horowitz, 1982). There are two facts to be considered. First, it is probable that the release of endorphins facilitates OBEs because of the analgesia and detachment, including a decrease in the body's awareness. Second, OBEs seem to correlate with personality variables like absorption, imagination, introversion, internal locus of control, and narcissistic person- 
ality (Lukianowicz, 1958; Tobacyk and Mitchell, 1987). In this kind of individual, it may be assumed that the mnesic image of the body is motivationally very important, and that, in the state induced by opioids, his or her own body could be a frequent category of complex visual hallucination. It is noteworthy to comment that in mnesic imagery of past events, the individual always see himself or herself from a "bird's-eye view" and does not have the actual somesthetic, visual, and auditory perception as in the actual episode.

(5) Afterdischarges propagate and induce several types of complex visual hallucinations, such as tunnel experiences, encounters with unearthly beings, religious figures, auras, and colors. Their spread to primary visual areas could induce simple visual hallucinations, like the brilliant lights reported in NDEs. Interestingly, that light seems to appear toward the end of the experience, suggesting that more distant cortical areas are recruited in the abnormal discharge. It is also possible that complex visual hallucinations could be induced directly through opioid psychotomimetic actions at kappa receptors and/or, eventually, through serotonergic, acetylcholinergic, and aminoacidergic mechanisms.

Other phenomena, such as alteration in temporal perception, can be understood by taking into account verbal mechanisms. Some authors, such as Robert Efron (1963), have suggested that linguistic mechanisms in the dominant hemisphere are important for normal time perception. In NDEs, as in other stressful situations like accidents and ingestion of hallucinogenic drugs (Masters and Houston, 1967), emotional self-preserving mechanisms dominate. That dominance, with obvious adaptive importance, might take precedence over linguistic mechanisms, producing alterations in time perception.

An important aspect that must be taken into account is the degree to which consciousness is involved in NDEs. The definition of consciousness is a rather complex subject (Saavedra-Aguilar and Gómez-Jeria, 1987; Caplan, 1986; Zimberg, 1977). Nevertheless, the first point to consider is that from the moment that the individual reports his or her experience, it is clear that it has been stored in the episodic memory, probably in a fragmented way. From memory experiments we know that affectively laden experiences are more easily remembered (Mesulam, 1986). Given that in NDEs the emotional components are supposed to be maximally active, the storage of part or all of the experience by memory mechanisms will be facilitated. 
Moreover, split-brain experiments support the idea that the verbal system can integrate emotions, perceptions, and memory traces in its own terms that are based on the individual's previous beliefs (Gazzaniga, 1985). One fundamental function of the verbal system appears to be the construction of logical, coherent, and explicative hypotheses based on the functioning of other cognitive and emotional systems. These hypotheses can sometimes be completely erroneous, but they are taken as absolute truth.

This explains the theory of cognitive dissonance, which states that when a person's beliefs, opinions, or attitudes are in disagreement as a consequence of that individual's freely produced behavior, a state of dissonance occurs. Cognition prior to the behavior is in conflict with the actual behavior. The organism does not allow that state of dissonance. Consonance is required, and is usually achieved by a verbal change in the prior value or belief. Within this view, it is the verbal system that is the final arbiter of our multiple mental systems (Gazzaniga and LeDoux, 1985).

This hypothesis supports the view that the actual NDE is later reconstructed in verbal terms in order to meet the individual's set of beliefs and previous cultural background, giving rise to another source of personal variability of the experience (see, for example, Abramovitch, 1988). A clear example of this variability is the transcultural comparison of NDE reports among Americans and Indians by Satwant Pasricha and Ian Stevenson (1986). In their study, 62\% of the Indians were "sent back" because of "mistake," compared to none of the American cases, while $81 \%$ of the Indian respondents were brought back from "other realms" by "messengers," again compared to none of the Americans.

Encounters with religious unearthly beings and the report that some of the respondents were ordered "to come back to life" by sacred figures (e.g., Jesus Christ), can be understood in terms of another posterior, logical, and culturally based recollection provided by the linguistic brain (Gazzaniga, 1985). Other situations in which posterior verbal reports do not necessarily convey the exact experience are certain epileptic experiences (Gloor, Olivier, Quesney, Andermann, and Horowitz, 1982), "mystical states" (Almond, 1982), the use of hallucinogenic drugs (Naranjo, 1973), shamanism (Eliade, 1960), dreams (Webb and Cartwright, 1978), and transcendental experiences (Kissin, 1986).

Seeing and hearing physically present persons (such as doctors and nurses) while apparently unconscious, later verified as being accurate, can be explained by assuming that before and after the episode the 
individual perceived a fragmentary reality (for example, somebody's face or the color of a dress), and later the verbal system provided a more or less logical and coherent report.

\section{Discussion}

We have presented a neurobiological explanation for NDEs that is based on their striking similarity to temporal lobe epilepsy. We are not saying that the NDE is a variety of TLE, but that its phenomenology arises from the abnormal functioning of similar portions of the central nervous system.

In a more general way, this model tries to answer the fundamental question of whether neurosciences and psychiatry are reconcilable (Pardes, 1986). The constraints imposed by each of these disciplines upon the other seem to be the only formal way to provide a solid scientific bridge between them. That implies that explanations or theories in the psychological domain that can be correlated with the state of the art of neurosciences will give the expected union.

Other functional explanations for NDEs are certainly possible, and the above model is merely an attempt to offer an initial and solid model for this phenomenon. Of course, while this model is in agreement with all existing relevant scientific evidence, it must be subjected to ongoing scientific testing of the most rigorous kind.

A very important point to stress is the origin of near-death experiences. Contrary to TLE, in which we are in the presence of a localized epileptic focus, the conditions leading to an NDE are multiple and variable. Whether or not all NDEs may be explained within a single model is a question that cannot yet be answered. What this model attempts to do is to provide the cerebral bases that are necessary to the mental experiences that occur in NDEs, and which, like other mental phenomena, occur in the domain of linguistic interactions among human beings. In that sense, our model is not a linear reductionist one.

Another point to comment on is why temporal lobe epilepsy phenomenology differs from NDE phenomenology. It is well known that in TLE, structural damage to limbic structures, like mesial sclerosis and malformations, is the basis of the condition. Thus the normal connections of the limbic system are disrupted, and the abnormal discharges would not be expected to propagate as they do in persons with epileptiform discharges in a structurally intact limbic system, as in NDEs.

On the other hand, it appears necessary to comment on why not all individuals under life-threatening situations have NDEs. As we stated 
above, NDEs are found in a high proportion of persons in that situation. Those who do not report NDEs can be assumed to differ in their genetic epileptogenic predisposition, functional differences (for example, less endorphin production under stress), degree of consciousness involvement, and/or capacity to reconstruct verbally a coherent history of the experience.

A point deserving further research is the similarity between NDE phenomenology and some kind of dreams (Van Eeden, 1969). During dream states there is a specific pattern of neuronal activity in the hippocampus and amygdala (Ravagnati, Halgren, Babb, and Crandall, 1977), suggesting again that limbic structures are involved in experiential mental phenomena.

Tradition weighs heavily in the adoption or rejection of models. In the case of NDEs, where strong religious elements appear coupled to hallucinatory and somesthetic phenomena, the temptation appears to consider models rooted in previous beliefs (for example, astral body explanations), without firm foundations in the light of present knowledge. Recent neurological analysis of some religious events, such as visionary experiences from written medieval sources (Kroll and Bachrach, 1982), and St. Paul's ecstatic visions (Landsborough, 1987) and sacred painting (Janz, 1987), which seem to correlate well with epileptic phenomenology, suggest that we are on the right path in separating physical elements from metaphysical ones.

\section{References}

Abramovitch, H. (1988). An Israeli account of a near-death experience: A case study of cultural dissonance, Journal of Near-Death Studies, 6, 175-184.

Almond, P. C. (1982). Mystical experience and religious doctrine Berlin: Mouton Publishers.

Babb, T. L., Wilson, C. L., and Isokawa-Akesson, I. (1987). Firing patterns of human limbic neurons during stereoencephalography (SEEG) and clinical temporal lobe seizures. Electroencephalography and Clinical Neurophysiology, 66, 467-482.

Brooks, S., Burrin, J., Cheetaw, M. E., Hall, G. M. Yeo, T., and Williams, C. (1988). The responses of the catecholamines and $\beta$-endorphin to brief maximal exercise in man. European Journal of Applied Physiology and Occupational Physiology, 57, 230-234.

Caplan, R. M. (1986). Exploring the concept of mind. Iowa City, IA: University of lowa Press.

Carr, D. B. (1981). Endorphins at the approach of death. Lancet, 1, 390.

Carr, D. B. (1982). Pathophysiology of stress-induced limbic lobe dysfunction: An hypothesis for NDEs. Anabiosis: The Journal of Near-Death Studies, 2, 75-89.

Clark, W. C., Yang, J. C., and Janal, M. N. (1984). Altered pain and visual sensitivity in humans: The effects of acute and chronic stress. Annals of the New York Academy of Science, 467, 116-129.

Critchley, M. (1979). The divine banquet of the brain. New York, NY: Raven Press. Pp. 1-12. 
Dingledine, R., Hynes, M. A., and King, G. L. (1986). Involvement of N-methylD-aspartate receptors in epileptiform bursting in the rat hippocampal slice. Journal of Physiology, 380, 175-189.

Eliade, M. (1964). Shamanism: Archaic techniques of ecstasy (W. R. Trask, trans.). Princeton, NJ: Princeton University Press.

Efron, R. (1963). Temporal perception, aphasia and déjà vu. Brain, 86, 403-424.

Fagg, G. E. (1985). L-glutamate, excitatory aminoacid receptors and brain function. Trends in Neuroscience, 8, 207-210.

Frederiks, J. A. M. (1969). Disorders of the body schema. Pp. 207-240 in P. J. Vinken and G. W. Bruyn (Eds.), Handbook of clinical neurology. Vol. 4: Disorders of speech, perception, and symbolic behavior. New York. NY: American Elsevier Publ. Co.

Frederiks, J. A. M. (1985). Paroxysmal neuropsychological disorders. Pp. 507-514 in P. J. Vinken, G. W. Bruyn, H. I. Klawans, and J. A. M. Frederiks (Eds.), Handbook of clinical neurology, Vol 45 (Revised series vol 1): Clinical neuropsychology. New York, NY: Elsevier Science Publ. Co.

Fujiwara, N., Higashi, H., Shimoki, K., and Yoshimura, M. (1987). Effects of hypoxia on rat hippocampal neurons in vitro. Journal of Physiology, 384, 131-151.

Gabbard, G. O., Twemlow, S. W., and Jones, F. C. (1981). Do "near-death experiences" occur only near death? Journal of Nervous and Mental Disease, 169, 374-377.

Gazzaniga, M. S. (1985). The social brain. New York, NY: Basic Books.

Gazzaniga, M. S., and LeDoux, J. E. (1985). The integrated mind. New York, NY: Plenum Press.

Gellman, R., and McNamara, I. (1984). Selective depletion of norepinephrine with the neurotoxin DSP4 facilitates kindling development in rats. Society for Neuroscience, $10,343$.

Gibson, G. E., and Blaas, J. P. (1979). Proportional inhibition of acetylcholine synthesis accompanying mild hypoxia and hypoglycemia. Journal of Neurochemistry, 27, 37-42.

Glennon, R. A. (1985). Involvement of serotonin in the action of hallucinogenic drugs. In R. A. Green (Ed.), Neuropharmacology of serotonin. Oxford, England: Oxford University Press.

Gloor, P. (1982). Temporal lobe epilepsy: Its possible contributions to the understanding of the functional significance of the amygdala and of its interaction with neocorticaltemporal mechanisms. Pp. 423-457 in B. E. Eleftherion (Ed.), The neurobiology of the amygdala New York, NY: Plenum Press.

Gloor, P., Olivier, A., Quesney, L. F., Andermann, F., and Horowitz, S. (1982). The role of the limbic system in experiential phenomena of temporal lobe epilepsy. Annals of Neurology, 12, 129-144.

Greyson, B. (1981). Toward a psychological explanation of near-death experiences: A response to Dr. Grosso's paper. Anabiosis: The Journal of Near-Death Studies, 1, 88-103.

Greyson, B. (1983a). The Near-Death Experience Scale: Construction, reliability, and validity. Journal of Nervous and Mental Disease, 171, 369-375.

Greyson, B. (1983b). The psychodynamics of near-death experiences. Journal of Nervous and Mental Disease, 171, 376-381.

Greyson, B. (1985). A typology of near-death experiences. American Journal of Psychiatry, 142, 967-969.

Greyson, B., and Stevenson, I. (1980). The phenomenology of near-death experiences. American Journal of Psychiatry, 137, 1193-1196.

Grosso, M. (1981). Toward an explanation of near-death phenomena. Anabiosis: The Journal of Near-Death Studies, 1, 3-26.

Gupta, A. R., Jeavons, P. M., Hughes, R. C., and Covanis, A. (1983). Aura in temporal lobe epilepsy: Clinical and electroencephalographic correlations. Journal of Neurology, Neurosurgery, and Psychiatry, 46, 1079-1083.

Halgren, E., Walter, R. D., Cherlow, D. G., and Crandall, P. H. (1978). Mental phenomena evoked by electrical stimulation of the human hippocampal formation and amyg. dala. Brain, 101, 83-117. 
Halgren, E., and Wilson C. L. (1985). Recall deficits produced by afterdischarges in the human hippocampal formation and amygdala. Electroencephalography and clinical Neurophysiology, 61, 375-380.

Hausser-Hauw, C., and Bancaud, J. (1987). Gustatory hallucinations in epileptic seizures. Brain, 110, 339-359.

Henriksen, S. J., Bloom, F. E., McCoy, F., Ling, N., and Guillemin, R. (1978). $\beta$-endorphin induces non-convulsive limbic seizures. Proceedings of the National Academy of Sciences, 75, 5221-5225.

Hiller, J. M., Itzhak, Y., and Simon, E. J. (1986). Limbic regions of the brain of Alzheimer's disease patients show selective changes in mu, delta and kappa opioid receptor binding. NIDA Research Monographs, 75, 559-562.

Hong, C. H., Woo, J. I., Suh, Y. H., Park, C. W., and Lee, C. K. (1987). Effect of ketamine on the acetylcholine concentration of various regions of rat brain. Seoul Journal of Medicine, 28, 347-351.

Isaacson, R. L. (1982). The limbic system. New York, NY: Plenum Press.

James, W. (1890). Principles of psychology. New York, NY: Holt.

Janz, D. (1986). Epilepsy, viewed metaphysically: An interpretation of the Biblical story of the epileptic boy and of Raphael's Transfiguration. Epilepsia, 27, 316-322.

Kelly, D. D. (1982). The role of endorphins in stress-induced analgesia. Annals of the New York Academy of Science, 398, 260-271.

Judson, I. R., and Wiltshaw, E. (1983). A near-death experience. Lancet, 2, 561-562.

Kissin, B. (1986). Conscious and unconscious programs in the brain. New York, NY: Plenum Press.

Kroll, J., and Bachrach, B. (1982). Visions and psychopathology in the Middle Ages. Journal of Nervous and Mental Disease, 170, 41-49.

Landsborough, D. (1987). St. Paul and temporal lobe epilepsy. Journal of Neurology, Neurosurgery, and Psychiatry, 50, 659-664.

Leitner, D. S. (1984). Alteration in other sensory modalities accompanying stress analgesia as measured by startle reflex modification. Annals of the New York Academy of Science, 467, 82-92.

Lukianowicz, N. (1958). Autoscopic phenomena, Archives of Neurology, 80, 199-220.

Masters, R. E. L., and Houston, J. (1967). The varieties of psychedelic experience. New York, NY: Dell.

McGinty, J. F., Kanamatsu, T., Obie, J., and Hong, J. S. (1986). Modulation of opioid peptide metabolism by seizures: differentiation of opioid subclasses. NIDA Research Monographs, 71, 89-101.

McIntosh, T. K., Fernyak, S., and Faden, A. I. (1986). Endogenous peptides, opiate receptors and traumatic brain injury. NIDA Research Monographs, 75, 527-530.

McLean, S., Rothman, R. B., and Herkenham, M. (1986). Autoradiographic localization of $\mu$ - and $\delta$-opioid receptors in the forebrain of the rat. Brain Research, 378, 49-60.

Mesulam, M. M. (1981). Dissociative states with abnormal temporal lobe EEG. Archives of Neurology, 38, 176-181.

Mesulam, M. M. (1986). Principles of behavioral neurology. Philadelphia, PA: F. A. Davis Co.

Mishkin, M., and Appenzeller, T. (1987). The anatomy of memory. Scientific American, 256, 62-71.

Modai, I., and Cygielman, G. (1986). Conversion hallucinations: A possible mental mechanism. Psychopathology, 19, 324-326.

Naranjo, C. (1973). Psychological aspects of the Yagé experience in an experimental setting. In M. J. Harner (Ed.), Hallucinations and shamanism. London, England: Oxford University Press.

Neumaier, J. F., Mailheau, S., and Chavkin, C. (1988). Opioid receptor-mediated responses in the dentate gyrus and CAI regions of the rat hippocampus. Journal of Pharmacology and Experimental Therapeutics, 244, 564-570.

Pardes, H. (1980). Neuroscience and psychiatry: Marriage or coexistence? American Journal of Psychiatry, 143, 1205-1212. 
Pasricha, S., and Stevenson, I. (1986). Near-death experiences in India. Journal of Nervous and Mental Disease, 174, 165-170.

Penfield, $W$. (1955). The role of the temporal cortex in certain psychical phenomena. Journal of Mental Science, 101, 451-465.

Plum F., and Pulsinelly, W. A. (1986). Cerebral metabolism and hypoxic-ischemic brain injury. Pp. 1086-1100 in A. K. Asbury, G. M. McKhann, and W. I. McDonald (Eds.), Diseases of the nervous system, Vol. 2. Philadelphia, PA: Ardmore Medical Books.

Ravagnati, L., Halgren, E., Babb, T. L., and Crandall, P. H. (1977). Activity of human hippocampal formation and amygdala neurons during sleep. Neuroscience Abstracts, 3, 471.

Rayport, M., and Ferguson, S. M. (1974). Qualitative modifications of sensory responses to amygdaloid stimulation in man by interview content and context. Electroencephalography and Clinical Neurophysiology, 34, 714.

Ring, K. (1980). Life at death: A scientific investigation of the near-death experience. New York, NY: Coward, McCann and Geoghegan.

Rogo, D. S. (1984). Ketamine and the NDE. Anabiosis: The Journal of Near-Death Studies, 4, 87-96.

Saavedra-Aguilar, J. C., and Gómez-Jeria, J. S. (1987). Towards a neurobiological model of self-consciousness. Revista Chilena de Neuro-Psiquiatria, 25, 247-251.

Sabom, M. S. (1982). Recollections of death: A medical investigation. New York, NY: Harper and Row.

Sabom, M. S., and Kreutziger, S. (1977a). The experience of near-death. Death Education, 1, 195-203.

Sabom, M. S., and Kreutziger, S. (1977b). Near-death experiences. New England Journal of Medicine, 297, 1071.

Saunders, R. C., and Rosene, D. L. (1988). A comparison of the afferents of the amygdala and the hippocampal formation in the Rhesus monkey. I: Convergence in the entorhinal, prorhinal and perirhinal cortices. Journal of Comparative Neurology, 271, 153-184.

Saunders, R. C., Rosene, D. L., and Van Hoesen, G. W. (1988). Comparison of the efferents of the amygdala and the hippocampal formation in the Rhesus monkey. II: Reciprocal and non-reciprocal connections. Journal of Comparative Neurology, 271, 185-207.

Schenk, L., and Bear, D. (1981). Multiple personality and related dissociative phenomena in patients with temporal lobe epilepsy. American Journal of Psychiatry, 138, 1311-1316.

Seifert, W. (1983). Neurobiology of the hippocampus. New York, NY: Academic Press. Siegel, R. (1980). The psychology of life after death. American Psychologist, 35, 911-931.

Siegel, R., and Hirschman, A. (1984). Hashish near-death experiences. Anabiosis: The Journal of Near-Death Studies, 4, 69-89.

Siesjo, B. K., and Wieloch, T. (1986). Epileptic brain damage: Pathophysiology and neurochemical pathology. Pp. 813-855 in A. V. Delgado-Escueta, A. A. Ward, D. M. Woodbury, and R. J. Porter (Eds.), Advances in Neurology, Vol 44, New York, NY: Raven Press.

Taylor, D. C., and Lochery, M. (1987). Temporal lobe epilepsy: Origin and significance of simple and complex auras. Journal of Neurology, Neurosurgery, and Psychiatry, 50, 673-681.

Tobacyk, J. J., and Mitchell, T. O. (1987). The out-of-body experience and personality adjustment. Journal of Nervous and Mental Disease, 175, 367-370.

Tulving, E. (1987). Multiple memory systems and consciousness. Human Neurobiology, $6,67-80$.

Van Eeden, F. (1969). A study of dreams. Pp. 145-158 in C. Tart (Ed.), Altered states of consciousness. New York, NY: John Wiley.

Webb, W. B., and Cartwright, R. D. (1978). Sleep and dreams. Annual Review of Psychology, 29, 223-252. 
Wieser, H. G. (1983). Depth recorded limbic seizures and psychopathology. Neuroscience and Biobehavioral Reviews, 7, 427.

Woodbury, D. (1984). Neurotransmitters and epilepsy: Distinguishing characteristics and unifying concepts. Federation Proceedings, 43, 2529-2531.

Zimberg, N. E. (1977). Alternate states of consciousness. London, England: Free Press. 